\title{
Updating a gas dynamics model using estimates for California sea lions (Zalophus californianus)
}

\author{
Matthew R. Hodanbosi ${ }^{\mathrm{a}, *}$, Blair Sterba-Boatwright ${ }^{\mathrm{b}}$, Andreas Fahlman ${ }^{\mathrm{a}}$ \\ ${ }^{a}$ Department of Life Sciences, Texas A\&M University-Corpus Christi, 6300 Ocean Drive, \\ Corpus Christi, TX, US 78412 \\ ${ }^{\mathrm{b}}$ Department of Mathematics and Statistics, Texas A\&M University-Corpus Christi, 6300 Ocean \\ Drive, Corpus Christi, TX, US 78412 \\ ${ }^{*}$ Corresponding author. \\ Email addresses: mhodanbosi@,outlook.com; mhodanbosi@,tamu.edu
}

Key words: diving physiology, modeling, marine mammals, gas dynamics 


\begin{abstract}
Theoretical models are used to predict how breath-hold diving vertebrates manage $\mathrm{O}_{2}, \mathrm{CO}_{2}$, and $\mathrm{N}_{2}$ while underwater. One recent gas dynamics model used available lung and tracheal compliance data from various species. As variation in respiratory compliance significantly affects alveolar compression and pulmonary shunt, the current study objective was to evaluate changes in model output when using species-specific parameters from California sea lions (Zalophus californianus). We explored the effects of lung and dead space compliance on the uptake of $\mathrm{N}_{2}, \mathrm{O}_{2}$, and $\mathrm{CO}_{2}$ in various tissues during a series of hypothetical dives. The updated parameters allowed for increased compliance of the lungs and an increased stiffness in the trachea. When comparing updated model output with a model using previous compliance values, there was a large decrease in $\mathrm{N}_{2}$ uptake but little change in $\mathrm{O}_{2}$ and $\mathrm{CO}_{2}$ levels. Therefore, previous models may overestimate $\mathrm{N}_{2}$ tensions and the risk of gas-related disease, such as decompression sickness (DCS), in marine mammals.
\end{abstract}




\section{Introduction}

Marine mammals routinely perform foraging dives to depths for durations that would be fatal to other mammals. The current record for most-extreme dive belongs to the Cuvier's beaked whale (Ziphius cavirostris), to nearly $3000 \mathrm{~m}$ for $137 \mathrm{~min}$ (Schorr et al., 2014). These species have physiological and anatomical traits that allow them to survive repeated exposure to these highpressure environments. One such adaptation is their ability to manage internal gases under changing pressure to minimize accumulation of $\mathrm{N}_{2}$ and thereby the risk of symptomatic gas bubbles.

The solubility of gases is directly related to the environmental pressure (Henry's law), and when animals are exposed to higher pressure, lung gases dissolve into the blood at higher partial pressures. In a hyperbaric environment, inert gases, like $\mathrm{N}_{2}$, dissolve into blood or tissues until the tension of the gas has been equilibrated, at which time the tissue is said to be saturated. If the pressure is reduced, the tissue or blood tension will eventually exceed the ambient partial pressure and the tissue is said to be supersaturated with the gas. Once the tissue is supersaturated, the gas may come out of solution and form bubbles. The likelihood for this to happen increases with the magnitude of supersaturation (Berghage et al., 1979; Fahlman et al., 2001; Weathersby et al., 1984). If these bubbles aggregate and become large enough, they can lodge and cause ischemia or initiate an immune response (Kayar et al., 1997). This is a condition known as decompression sickness (DCS), or "the bends". To better understand the etiology of DCS and other gas-related diseases, it is therefore important to understand how gases (both inert and biological) behave in tissues at changing pressures.

The rate and amount of gases exchanged between the lungs and the blood are driven in part by the compliance of the respiratory system and the surface area of the alveoli (Bostrom et al., 
2008). To minimize $\mathrm{N}_{2}$ uptake and the risk of DCS, it has been suggested the respiratory anatomy of marine mammals allows the alveoli to collapse at shallow depths, at which point gas exchange ceases (Scholander, 1940). Marine mammals are equipped with a relatively stiff upper respiratory system and elastic chest and alveoli compared to terrestrial mammals (Cozzi et al., 2005; Fahlman et al., 2014a, 2011; Leith, 1979; Moore et al., 2014). As an animal dives, the gasfilled spaces compress, which increases the partial pressures of the gases in the alveoli (Boyle's Law). In turn, this increase of partial pressure in the lungs causes more gas to diffuse into the blood. However, the pressure also compresses the gases in the lung and as the chest and alveoli are compliant, these structures collapse faster and push the gas into the conducting airways. This results in a pulmonary shunt that increases with depth (Kooyman and Sinnett, 1982) and eventually cause gas exchange to cease (McDonald and Ponganis, 2012). Because these physiological processes occur at elevated pressures, it is logistically challenging to study gas dynamics in live, free-diving animals.

Mathematical models are useful tools that allow researchers to study physiological systems. For example, these models may help define which variables control complex physiological responses. However, any model is limited by the accuracy of its assumptions and the input parameters. Current models aimed at defining the uptake and removal of metabolic $\left(\mathrm{O}_{2}\right.$ and $\left.\mathrm{CO}_{2}\right)$ and inert gases $\left(\mathrm{N}_{2}\right)$ in breath-hold diving marine vertebrates often lack species-specific knowledge of physiological responses or parameters. For example, the changes in cardiac output during diving are often assumed to correlate with changes in heart rate and have only been measured in a limited number of marine mammal species (Miedler et al., 2015; Ponganis et al., 2006, 1991, 1990). Similarly, the changes in gas diffusion across the lung as pressure changes are not well understood. Therefore, mathematical models that utilize respiratory compliance data 
have been used to estimate diffusion rates and the resulting gas tensions in blood and tissues (Bostrom et al., 2008; Fahlman et al., 2009, 2006).

In marine mammals, empirical physiological data, such as compliance estimates, are challenging to collect and often not available for most species. Therefore, previous diving models used data collected from a multitude of species, including terrestrial mammals such as sheep and dogs, which differ greatly in respiratory anatomy from marine mammals (Bostrom et al., 2008; Fahlman et al., 2006; Moore et al., 2014). However, the importance of species-specific physiological parameters in modeling gas dynamics is currently not known. Recently, anatomical and physiological data have been collected from living California sea lions (Zalophus californianus), as well as from excised respiratory tissues. These new data allow for the use of species-specific parameters to estimate gas dynamics in an individual during a series of dives. This paper will explore the significance of species-specific parameters in a diving model by comparing these with parameters previously used based on data from terrestrial mammals.

\section{Materials and Methods}

\subsection{Model}

The model described in this paper is an updated version of the model used by Fahlman et al. (2009) which combined a gas dynamics (Fahlman et al., 2006) and lung compression model (Bostrom et al., 2008). The combined model estimated changes in pulmonary, blood and tissue $\mathrm{O}_{2}, \mathrm{CO}_{2}$, and $\mathrm{N}_{2}$ levels during breath-hold diving. The body was divided into 5 different compartments where gases were exchanged: blood, brain, central circulation, fat, and muscle. These compartments were grouped as fast (blood, brain, central circulation), intermediate (muscle), and slow (fat) based on their tissue-time constants and blood flow (Fahlman et al., 
2009). In the current effort, these stores were unchanged. The updated model parameters were based on respiratory compliance data collected from anesthetized California sea lions, as well as from excised tissues from deceased specimens (Fahlman et al., 2014a; Moore et al., 2014).

\subsection{Dive Parameters}

A simulated dive bout, a series of repeated dives with a short intervening surface interval, was created that consisted of 6 dives, with an ascent and decent rate of $1.5 \mathrm{~m} \cdot \mathrm{sec}^{-1}$, to a pressure of 30.1 atmospheres (ATA; $291 \mathrm{~m}$ ), and a $400 \mathrm{sec}$ surface interval (Figure 1). An initial surface interval of $400 \mathrm{sec}$ was included to allow the initial gas levels to stabilize prior to the start of the dive bout. This dive series was based on a previously published dive data collected from a freeranging female California sea lion (McDonald and Ponganis, 2013).

\subsection{Anatomical parameters}

Body mass was estimated as the mean body mass of the male California sea lions from which the updated parameter estimates originated (64 kg, N=3; Fahlman et al., 2014). Diving lung volume (i.e., the volume of gas in the lungs as the animal initiates a dive) was estimated as the mean of previously published diving lung volumes (percentage of total lung capacity) collected from forced dived California sea lions ( $\mathrm{N}=2$; Kooyman and Sinnett, 1982). The volume of the dead space (i.e., trachea and bronchi) was estimated at 5\% TLC based on previously published data (Kooyman and Sinnett, 1979; Moore et al., 2014). Because the chest wall is much more compliant than the respiratory system, it was ignored in the model and the pressure placed on the respiratory system was equal to ambient pressure (Fahlman et al., 2014a). 


\subsection{Physiological parameter estimates}

The pressure-volume (P-V) relationship from the lungs of 3 live adult California sea lions under anesthesia (Fahlman et al., 2014a) and excised conducting airways (Moore et al., 2014), as well as pulmonary shunt, were fit to the following equations. The P-V relationship for the alveolar space was:

$$
\mathrm{V}_{\mathrm{A}, \mathrm{N}}=\mathrm{a}\left(1+\mathrm{e}^{-\mathrm{c}(-\mathrm{b}-\mathrm{P}} \mathrm{A,S}\right)^{-1}
$$

where $a, b, c$, are fitting parameters, $\mathrm{P}_{\mathrm{A}, \mathrm{S}}$ is the structural pressure of alveoli (i.e., alveolar compliance) and $\mathrm{V}_{\mathrm{A}, \mathrm{N}}$ is the normalized alveolar volume $\left(\mathrm{V}_{\mathrm{A}} \cdot \mathrm{TAC}^{-1}\right.$; Bostrom et al., 2008). To estimate tracheal compliance, $\mathrm{P}-\mathrm{V}$ data from 3 California sea lions were fitted to the following equation:

$$
\mathrm{V}_{\mathrm{D}, \mathrm{N}}=\left(1-\mathrm{P}_{\mathrm{D}, \mathrm{S}}(0.0981 \mathrm{Kp})^{-1}\right)^{-1 / \mathrm{n}}
$$

where $K p$ and $n$ are fitting parameters, $\mathrm{P}_{\mathrm{D}, \mathrm{S}}$ is the structural pressure of dead space (i.e., dead space compliance) and $\mathrm{V}_{\mathrm{D}, \mathrm{N}}$ is the normalized dead space volume $\left(\mathrm{V}_{\mathrm{D}} \cdot \mathrm{V}_{\mathrm{D}, \mathrm{o}}{ }^{-1}\right.$; Bostrom et al., 2008). Previously published pressure-shunt data collected from 2 California sea lions (Kooyman and Sinnett, 1982) were fit to the following pulmonary shunt equation:

$$
\text { Shunt }=1-\left(\mathrm{g} \cdot\left(\mathrm{DV}_{\mathrm{A}} \cdot \mathrm{V}_{\mathrm{A}}{ }^{-1}\right)^{-\mathrm{h}}\right)
$$


where $a$ and $b$ are fitting parameters, where $\mathrm{DV}_{\mathrm{A}}$ is the estimated alveolar volume at depth and $\mathrm{V}_{\mathrm{A}}$ is the maximum alveolar volume (Fahlman et al., 2009). The parameter values in this paper were estimated using either nonlinear mixed effects models (alveolar compliance) or nonlinear least squares models (dead space compliance and pulmonary shunt). For equations 1 and 2, the use of individual animals as levels of a random grouping factor was tested. The fitting parameters of the models were tested both as fixed values across all individuals, or permitted to vary individually by animal. Corrected Akaike information criteria (AICc; Burnham and Anderson, 2003) was used to determine the optimal choices of fixed versus random parameters.

End-dive tissue gas tension differences were calculated using the following equation:

$$
\text { Percent difference }=\left[(\text { old-new }) \cdot \text { old }^{-1}\right] \cdot 100 \%
$$

where old is the gas tension value from the model run using the old parameters and new is the gas tension value from the model run using the new parameters. The values were collected 3 seconds after surfacing to allow the lung gasses to stabilize prior to analysis. Because all fastloading tissues had similar tissue-time constants and gas tension outputs, a single representative tissue (i.e., brain) was chosen for analysis of this tissue type.

All model fitting was performed using R version 3.2.1 (R Core Team, 2015) including the nlme package version 3.1-124 (Pinheiro et al., 2016) and the MuMIn package version 1.15.6 (Barton, 2015). The physiological modeling was performed using MATLAB (R2010a) version 7.10.0.499 (MathWorks Inc., 2010). 


\section{Results}

\subsection{Updated Model Parameters}

Using a nonlinear mixed effects model, where $a$ was a fixed factor across individuals and $b$ and $c$ were random factors between individual, alveolar compliance was greater using the updated parameter estimates (Error! Reference source not found.; Figure 3). Using a nonlinear least squares model, where $K p$ and $n$ were fixed factors, tracheal compliance was less using the updated parameter estimates (Error! Reference source not found.; Figure 3). Using a nonlinear least squares model, where $g$ and $h$ were fixed factors, pulmonary shunting was slightly greater, and therefore more efficient at reducing tissue and blood $\mathrm{N}_{2}$ levels, using the updated parameter estimates (Table 1; Figure 5).

\subsection{Model $P_{N_{2}}$ Output}

Using a simulated dive data set, the model output using the updated parameter estimates had lower $\mathrm{P}_{\mathrm{N}_{2}}$ estimates than the model output using the former parameter estimates in all tissue types: fast-loading tissues (e.g., brain, Figure 6), intermediate-loading tissues (e.g., muscle, Figure 7), and slow-loading tissues (e.g., fat, Figure 8). The end-dive $\mathrm{P}_{\mathrm{N}_{2}}$ differences were $51.2 \pm 0.1 \%$ for brain, $39.6 \pm 0.4 \%$ for muscle, and $22.6 \pm 7.7 \%$ for fat.

\subsection{Model $\mathrm{P}_{\mathrm{O}_{2}}$ Output}

The model output using the updated parameter estimates had similar $\mathrm{P}_{\mathrm{O}_{2}}$ estimates to the model output using the former parameter estimates in all tissue types: fast-loading tissues (e.g., brain), 
intermediate-loading tissues (e.g., muscle) and slow-loading tissues (e.g., fat). The end-dive $\mathrm{P}_{\mathrm{O}_{2}}$ differences were $<0.1 \%$ for brain, $5.61 \pm 0.1 \%$ for muscle, and $<0.1 \%$ for fat (Figure 9 ).

\subsection{Model $\mathrm{P}_{\mathrm{CO}_{2}}$ Output}

Also, the model output using the updated parameter estimates had similar $\mathrm{P}_{\mathrm{CO}_{2}}$ estimates to the model output using the former parameter estimates in all tissue types: fast-loading tissues (e.g., brain), intermediate-loading tissues (e.g., muscleError! Reference source not found.) and slow-loading tissues (e.g., fat). The end-dive $\mathrm{P}_{\mathrm{CO}_{2}}$ differences were $1.53 \pm 0.1 \%$ for brain, $0.5 \pm 0.1 \%$ for muscle, and $0.3 \pm 0.1 \%$ for fat (Figure 9 ).

\section{Discussion}

In this paper, we present a model to estimate gas exchange during breath-hold diving. This is the first attempt to quantify gas exchange using species-specific parameters for a marine mammal's respiratory system. Updated parameter estimates from species-specific data show large differences in $\mathrm{N}_{2}$ tensions in all tissue types as compared to the previous result that did not use species-specific compliance estimates. In addition, there was almost no difference in $\mathrm{CO}_{2}$ and $\mathrm{O}_{2}$ tensions between the updated and previous models. New input parameters were based on data collected from excised tissues from deceased animals or live animals under anesthesia, while previous input parameters were based solely on excised tissues. Due to the lack of empirical data on the physiology of diving marine mammals, many factors in the model are likely oversimplified. Despite these limitations, the updated model provides interesting results that can help generate hypotheses as to the mechanics of gas exchange during diving. 
Scholander (1940) proposed that to avoid exposure to extreme $\mathrm{N}_{2}$ tensions, marine mammals have rigid upper-airways and flexible alveoli that collapse as the animal dives. However, research has shown that the conducting airways do experience some degree of compression (Kooyman et al., 1970). Tracheal compliance estimates used in previous models were based on data from terrestrial mammals (Aljuri et al., 1999). Respiratory compliance data for marine mammals are sparse but available for a few species (Fahlman et al., 2015, 2014a; Leith, 1979; Moore et al., 2014; Olsen et al., 1969). The tracheal compliance estimates for California sea lions show a greater degree of stiffness than the estimates used in previous models (Bostrom et al., 2008; Fahlman et al., 2009). The new data used in the updated gas exchange model support Scholander's hypothesis, that the stiff upper-airways are used as a reservoir for gases while the alveolar space collapses in order to limit gas exchange at high pressures. The increased stiffness of the dead space and the increased compliance of the alveoli in the updated model allow the alveoli to collapse at a lower pressure than previously estimated. Thus, gas exchange occurs over a reduced pressure range, decreasing the amount of $\mathrm{N}_{2}$ that enters the body.

While there was a large difference in $\mathrm{N}_{2}$ tensions, little difference was observed in $\mathrm{O}_{2}$ and $\mathrm{CO}_{2}$ tensions between the two models. The models utilized the same metabolic rate and respiratory quotients during the dive series, so $\mathrm{O}_{2}$ usage and $\mathrm{CO}_{2}$ production was similar for both models. Even though lung collapse occurred earlier in the model using the updated parameters, enough $\mathrm{O}_{2}$ was in the circulatory system prior to collapse to allow the animal to oxygenate the tissues without reaching its aerobic dive limit.

Because models are constrained by their input parameters, it is crucial to use the most accurate and reliable data available. The new data used to estimate the parameters in this model came from animals at a rehabilitation facility (Fahlman et al., 2014a; Moore et al., 2014). One 
potential problem with using physiological data from animals undergoing rehabilitation is that they may have suffered from respiratory disease when they were tested. However, only animals without any signs of pulmonary disease were selected for these respiratory compliance studies (Fahlman et al., 2014a; Moore et al., 2014).

In addition, tracheal compliance parameters were estimated using excised tracheas that were taken from deceased animals that had either asphyxiated during fisheries interactions or had been euthanized for reasons other than being used for this research project (Fahlman et al., 2014a, 2011; Moore et al., 2014). Since the tracheas were no longer interacting with surrounding tissues, such as the lungs and the pleural cavity, these data may not reflect tracheal compliance in live, free-diving individuals. Therefore, the compliance may differ in the excised tracheas than tracheas in a complete respiratory system. Thus, imaging studies of live animals may help to improve our understanding of the mechanical properties of the respiratory system in marine mammal and how it behaves under pressure.

The mathematical formulas used in a model are also important to the realism of the output of the model. Because little is known about the physiology of gas exchange in the lungs of diving marine mammals, many of the equations used in the model are based on simplified, theoretical equations. For example, since the gas concentration gradient in the lungs is not well understood, it is assumed that gases are mixed ubiquitously throughout the lungs in this model. However, previous studies in humans have shown that inhaled gases are not mixed uniformly throughout the lungs (Fowler, 1949; Krogh and Lindhard, 1917; Roelsen, 1938). In addition, lung gas concentrations are immediately changed to surface values once the animal reaches the surface in the model, which does not reflect the effect of alveolar ventilation and alternating alveolar gas 
concentrations during recovery of a free-diving animal (Kooyman et al., 1971). Therefore, the model may underestimate the time needed for tissues to off-gas at the surface.

In the updated model, the decreased $\mathrm{N}_{2}$ tension output for all tissue types indicate a lower risk of gas-related diseases in California sea lions than would be estimated using the previous model parameters (Fahlman et al., 2009). In addition, the results of the current study imply that the risk gas-related diseases in California sea lions is generally low. Thus, this species may be able to significantly change their dive behavior in response to anthropogenic disturbances, such as Naval sonar or environmental change, while minimally increasing the risk of gas bubble disease.

The output of this updated model indicates that species-specific parameters are important to best estimate the physiological processes involved with a dive. Empirical data on the anatomy of different marine mammals is crucial in estimating how variations in gas exchange parameters affect blood and tissue gas levels. Once species-specific anatomical data are available, the model input can be adjusted to improve the potential physiological impact of changes in the environment, such as anthropogenic noise or climate change. Species that appear especially prone to decompression sickness (DCS), such as Cuvier's beaked whales (Fahlman et al., 2014b; Fernández et al., 2005; Houser et al., 2001; Jepson et al., 2003) are of particular interest, as the output of the updated model suggests that previous blood and tissue $\mathrm{P}_{\mathrm{N}_{2}}$ estimates may be overestimated.

Although there is no evidence that California sea lions are susceptible to DCS, they make a great model species for marine mammal diving physiology. While recent reports have indicated that California sea lions may experience gas bubble disease, this may have been secondary to barotrauma (Van Bonn et al., 2013, 2011). Due to their life history traits, in particular the 
capability of this species to spend extended periods of time on land, researchers often choose this species for studies that require tagging and handling compared to other marine mammals. Therefore, more physiological data are available on California sea lions than species that are prone to DCS, such as beaked whales. Until more physiological data become available from cetaceans, data from California sea lions can be used inform the model and provide estimates on the risk of DCS in other diving marine mammal species.

In order to better estimate the effects of lung collapse on gas dynamics, a critical next step is to collect empirical data from live, free-diving animals, and compare those to the gas tension output of the model. In a previous study we showed that the chest wall compliance in this species is significantly greater as compared to the alveolar compliance (see Fig. 1 in Fahlman et al., 2014a). Thus, the chest wall compliance data does not have an effect on internal pressure and should not affect the collapse depth of the alveoli. By adding physiological parameters not currently included in the model, and comparing the updated model to empirical data, the accuracy of the model can continuously be increased. The process of updating and vetting the model will allow us to estimate how changes in diving behavior will affect gas tensions in marine mammals. These estimates can then be used to estimate the risk different species face in response to various environmental stressors or ecological changes.

\section{Acknowledgments}

We would like to thank Dr. Birgette McDonald and Dr. Paul Ponganis for providing a dive data set for California sea lions that was used to develop the hypothetical dive data. Funding for this project was provided by the Office of Naval Research (Award \# N000141512221 and ONR YIP Award \# N000141410563). 


\section{Citations}

Aljuri, N., Freitag, L., Venegas, J.G., 1999. Modeling expiratory flow from excised tracheal tube laws. J. Appl. Physiol. 87, 1973-1980.

Barton, K., 2015. MuMIn: Multi-Model Inference (R package).

Berghage, T.E., David, T.D., Dyson, C. V., 1979. Species differences in decompression. Undersea Biomed. Res. 6, 1-13.

Bostrom, B.L., Fahlman, A., Jones, D.R., 2008. Tracheal compression delays alveolar collapse during deep diving in marine mammals. Respir. Physiol. Neurobiol. 161, 298-305. doi:10.1016/j.resp.2008.03.003

Burnham, K.P., Anderson, D.R., 2003. Model selection and multimodel inference: a practical information-theoretic approach. Springer Science \& Business Media.

Cozzi, B., Bagnoli, P., Acocella, F., Costantino, M.L., 2005. Structure and biomechanical properties of the trachea of the striped dolphin Stenella coeruleoalba: evidence for evolutionary adaptations to diving. Anat. Rec. A. Discov. Mol. Cell. Evol. Biol. 284, 50010. doi:10.1002/ar.a.20182

Fahlman, A., Hooker, S.K., Olszowka, A., Bostrom, B.L., Jones, D.R., 2009. Estimating the effect of lung collapse and pulmonary shunt on gas exchange during breath-hold diving: the Scholander and Kooyman legacy. Respir. Physiol. Neurobiol. 165, 28-39. doi:10.1016/j.resp.2008.09.013

Fahlman, A., Loring, S.H., Ferrigno, M., Moore, C., Early, G., Niemeyer, M., Lentell, B., Wenzel, F., Joy, R., Moore, M.J., 2011. Static inflation and deflation pressure-volume curves from excised lungs of marine mammals. J. Exp. Biol. 214, 3822-3828. 
doi:10.1242/jeb.056366

Fahlman, A., Loring, S.H., Levine, G., Rocho-Levine, J., Austin, T., Brodsky, M., 2015. Lung mechanics and pulmonary function testing in cetaceans. J. Exp. Biol. 218, 2030-2038. doi:10.1242/jeb.119149

Fahlman, A., Loring, S.H., Shawn, P., Haulena, M., Trites, A.W., Fravel, V.A., Bonn, W.G. Van, Trumble, S.J., 2014a. Inflation and deflation pressure-volume loops in anesthetized pinnipeds confirms compliant chest and lungs. Front. Physiol. 5, 433-439. doi:10.3389/fphys.2014.00433

Fahlman, A., Olszowka, A., Bostrom, B., Jones, D.R., 2006. Deep diving mammals: Dive behavior and circulatory adjustments contribute to bends avoidance. Respir. Physiol. Neurobiol. 153, 66-77. doi:10.1016/j.resp.2005.09.014

Fahlman, A., Tikuisis, P., Himm, J.F., Weathersby, P.K., Kayar, S.R., 2001. On the likelihood of decompression sickness during $\mathrm{H} 2$ biochemical decompression in pigs. J. Appl. Physiol. 91, $2720-2729$.

Fahlman, A., Tyack, P.L., Miller, P.J.O., Kvadsheim, P.H., 2014b. How man-made interference might cause gas bubble emboli in deep diving whales. Front. Physiol. 5, 13. doi:10.3389/fphys.2014.00013

Fernández, A., Edwards, J.F., Rodríguez, F., Espinosa de los Monteros, A., Herráez, P., Castro, P., Jaber, J.R., Martín, V., Arbelo, M., 2005. "Gas and fat embolic syndrome” involving a mass stranding of beaked whales (family Ziphiidae) exposed to anthropogenic sonar signals. Vet. Pathol. 42, 446-457. doi:10.1354/vp.42-4-446

Fowler, W.D., 1949. Lung Function Studies. III. Uneven pulmunary ventilation in normal subjects and in patients with pulmonary disease. J. Appl. Physiol. 2, 283-299. 
Houser, D.S., Howard, R., Ridgway, S., 2001. Can Diving-induced Tissue Nitrogen Supersaturation Increase the Chance of Acoustically Driven Bubble Growth in Marine Mammals? J. Theor. Biol. 213, 183-195. doi:10.1006/jtbi.2001.2415

Jepson, P.D., Arbelo, M., Deaville, R., Patterson, I.A.P., Castro, P., Baker, J.R., Degollada, E., Ross, H.M., Herráez, P., Pocknell, A.M., Rodríguez, F., Howie, F.E., Espinosa, A., Reid, R.J., Jaber, J.R., Martin, V., Cunningham, A.A., Fernández, A., 2003. Gas-bubble lesions in stranded cetaceans. Nature 425, 575-576. doi:10.1038/425575a

Kayar, S.R., Aukhert, E.O., Axley, M.J., Homer, L.D., Harabin, A.L., 1997. Lower decompression sickness risk in rats by intravenous injection of foreign protein. Undersea Hyperb. Med. 24, 329-335.

Kooyman, G.L., Hammond, D.D., Schroeder, J.P., 1970. Bronchograms and tracheograms of seals under pressure. Science 169, 82-84. doi:10.1126/science.169.3940.82

Kooyman, G.L., Kerem, D.H., Campbell, W.B., Wright, J.J., 1971. Pulmonary function in freely diving Weddell seals, Leptonychotes weddelli. Respir. Physiol. 12, 271-282. doi:10.1016/0034-5687(73)90003-0

Kooyman, G.L., Sinnett, E.E., 1982. Pulmonary shunts in harbor seals and sea lions during simulated dives to depth. Physiol. Zool. 55, 105-111.

Kooyman, G.L., Sinnett, E.E., 1979. Mechanical properties of the harbor porpoise lung, Phocoena phocoena. Respir. Physiol. 36, 287-300.

Krogh, A., Lindhard, J., 1917. The volume of the dead space in breathing and the mixing of gases in the lungs of man. J. Physiol. 51, 59-90.

Leith, D.E., 1979. Comparative mammalian respiratory mechanics. Am. Rev. Respir. Dis. 19, $485-510$. 
MathWorks Inc., T., 2010. MATLAB version 7.10.0 (R2010a). Natick, Massachusetts.

McDonald, B.I., Ponganis, P.J., 2013. Insights from venous oxygen profiles: oxygen utilization and management in diving California sea lions. J. Exp. Biol. 216, 3332-41. doi:10.1242/jeb.085985

McDonald, B.I., Ponganis, P.J., 2012. Lung collapse in the diving sea lion: hold the nitrogen and save the oxygen. Biol. Lett. 8, 1047-9. doi:10.1098/rsbl.2012.0743

Miedler, S., Fahlman, A., Valls Torres, M., Alvaro Alvarez, T., Garcia-Parraga, D., 2015. Evaluating cardiac physiology through echocardiography in bottlenose dolphins: using stroke volume and cardiac output to estimate systolic left ventricular function during rest and following exercise. J. Exp. Biol. 218, 3604-3610. doi:10.1242/jeb.131532

Moore, C., Moore, M., Trumble, S., Niemeyer, M., Lentell, B., McLellan, W., Costidis, A., Fahlman, A., 2014. A comparative analysis of marine mammal tracheas. J. Exp. Biol. 217, 1154-66. doi:10.1242/jeb.093146

Olsen, C.R., Hale, F.C., Elsner, R., 1969. Mechanics of ventilation in the pilot whale. Respir. Physiol. 7, 137-149. doi:10.1016/0034-5687(69)90001-2

Pinheiro, J., Bates, D., DebRoy, S., Sarkar, D., Heisterkamp, S., B.V., W., 2016. Linear and Nonlinear Mixed Effects Models (R package). doi:http://dx.doi.org/10.18637/jss.v067.i01

Ponganis, P.J., Kooyman, G.L., Zornow, M.H., 1991. Cardiac output in swimming California sea lions, Zalophus californianus. Physiol. Zool. 64, 1296-1306.

Ponganis, P.J., Kooyman, G.L., Zornow, M.H., Castellini, M.A., Croll, D.A., 1990. Cardiac output and stroke volume in swimming harbor seals. J. Comp. Physiol. B 160, 473-482. doi:10.1007/BF00258974

Ponganis, P.J., Stockard, T.K., Levenson, D.H., Berg, L., Baranov, E.A., 2006. Cardiac output 
and muscle blood flow during rest-associated apneas of elephant seals. Comp. Biochem. Physiol. - A Mol. Integr. Physiol. 144, 105-111. doi:10.1016/j.cbpa.2006.02.009

R Core Team, 2015. R: A Language and Environment for Statistical Computing.

Roelsen, E., 1938. Fractional analysis of alveolar air after inspiration of hydrogen as a method for the determination of the distribution of inspired air in the lungs . Acta Med. Scand. 95, $452-482$.

Scholander, P.F., 1940. Experimental investigations on the respiratory function in diving mammals and birds. Hvalrad. Skr. 22, 1-131.

Schorr, G.S., Falcone, E.A., Moretti, D.J., Andrews, R.D., 2014. First long-term behavioral records from Cuvier's beaked whales (Ziphius cavirostris) reveal record-breaking dives. PLoS One 9, e92633. doi:10.1371/journal.pone.0092633

Van Bonn, W., Dennison, S., Cook, P., Fahlman, A., 2013. Gas bubble disease in the brain of a living California sea lion (Zalophus californianus). Front. Physiol. 4, 1-6. doi:10.3389/fphys.2013.00005

Van Bonn, W., Montie, E., Dennison, S., Pussini, N., Cook, P., Greig, D., Barakos, J., Colegrove, K., Gulland, F., 2011. Evidence of injury caused by gas bubbles in a live Marine Mammal: Barotrauma in a California sea lion Zalophus californianus. Dis. Aquat. Organ. 96, 89-96. doi:10.3354/dao02376

Weathersby, P.K., Homer, L.D., Flynn, T.E., 1984. On the likelihood of decompression sickness. J. Appl. Physiol. Respir. Environ. Exerc. Physiol. 57, 815-825. 
Table

Table 1. The previous and updated parameter estimate values used for the equations used in the gas dynamics model. 


\section{Figures}

Figure 1. A simulated dive profile used in the model to estimate tissue-specific gas tensions at depth.

Figure 3. Normalized lung volume estimates using the former parameter estimates (darker lines) and the updated parameter estimates (lighter lines).

Figure 5. Shunt estimates using the former parameter estimates (black) and the updated parameter estimates (red).

Figure 6. Brain (a fast-loading tissue) $\mathbf{P}_{\mathrm{N}_{2}}$ estimates using the former parameter estimates (black) and the updated parameter estimates (red) using a simulated dive profile from a California sea lion.

Figure 7. Muscle (an intermediate-loading tissue) $\mathbf{P}_{\mathrm{N}_{2}}$ estimates using the former parameter estimates (black) and the updated parameter estimates (red) using a simulated dive profile from a California sea lion.

Figure 8. Fat (a slow-loading tissue) $\mathrm{P}_{\mathrm{N}_{2}}$ estimates using the former parameter estimates (black) and the updated parameter estimates (red) using a simulated dive profile from a California sea lion. 
Figure 9. End-dive $\mathrm{P}_{\mathrm{O}_{2}}$ and $\mathrm{P}_{\mathrm{CO}_{2}}$ differences ([old-new]/old*100\%) between model runs with old and new parameters for fast-loading (brain), intermediate-loading (muscle), and slow-loading (fat) tissues. 


\section{Table 1}

\begin{tabular}{|l|l|l|}
\hline \multicolumn{3}{|c|}{ Alveolar Compliance Equation (Eq. 1) } \\
\hline Parameter & Former Value & Updated Value \\
\hline$a$ & 1.11 & $1.03 \pm 0.07$ \\
\hline$b$ & 1.23 & $1.76 \pm 0.27$ \\
\hline$c$ & 1.34 & $1.80 \pm 0.14$ \\
\hline \multicolumn{3}{|c|}{ Tracheal Compliance Equation (Eq. 2) } \\
\hline Parameter & Former Value & Updated Value \\
\hline$K p$ & -12.78 & $-12.54 \pm 11.90$ \\
\hline$n$ & 0.907 & $4.24 \pm 2.46$ \\
\hline \multicolumn{3}{|c|}{ Pulmonary Shunt Equation (Eq. 3) } \\
\hline Parameter & Former Value & Updated Value \\
\hline$g$ & -1.06 & $-1.07 \pm 0.01$ \\
\hline$h$ & 0.17 & $0.21 \pm 0.01$ \\
\hline
\end{tabular}




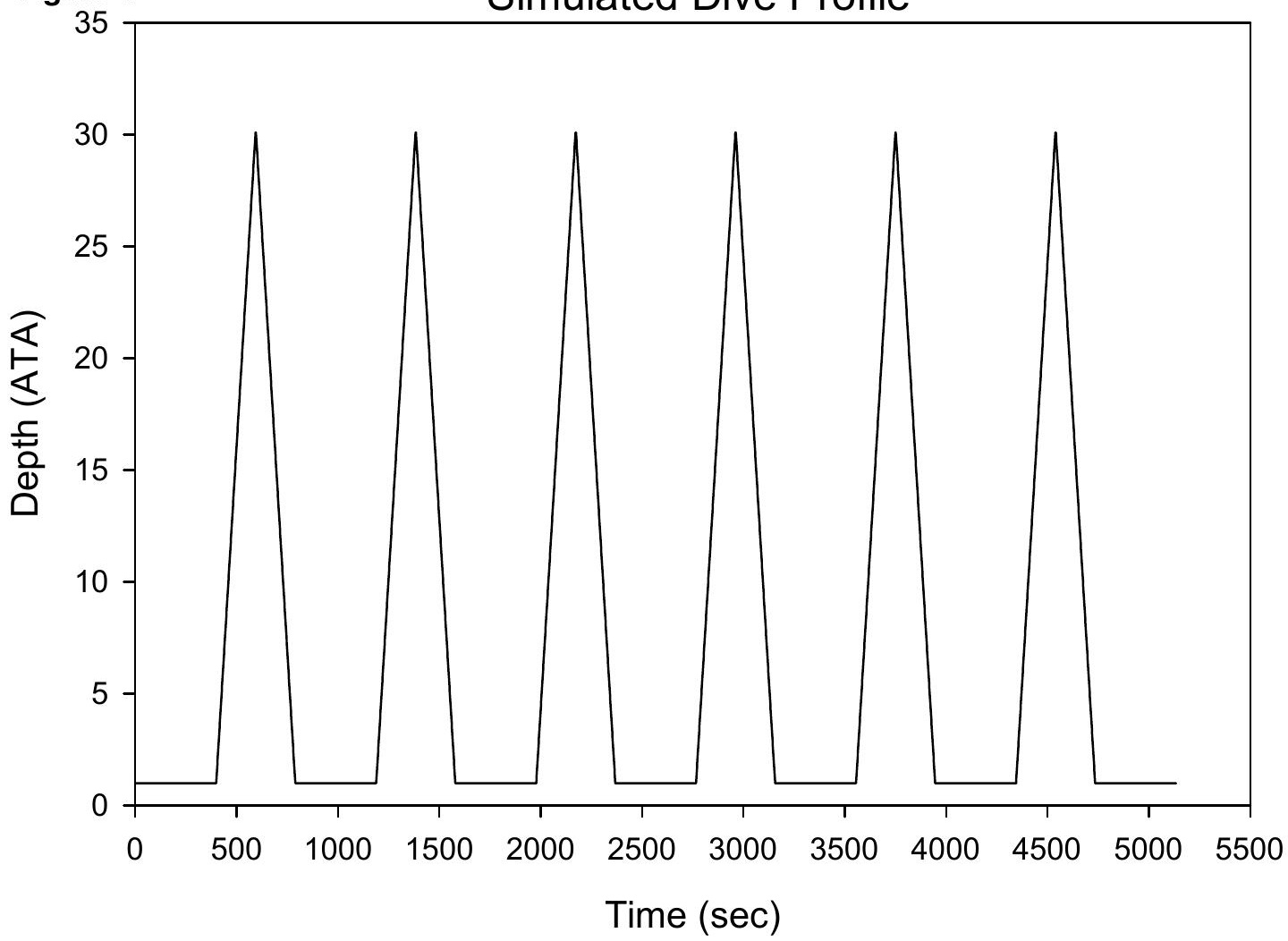




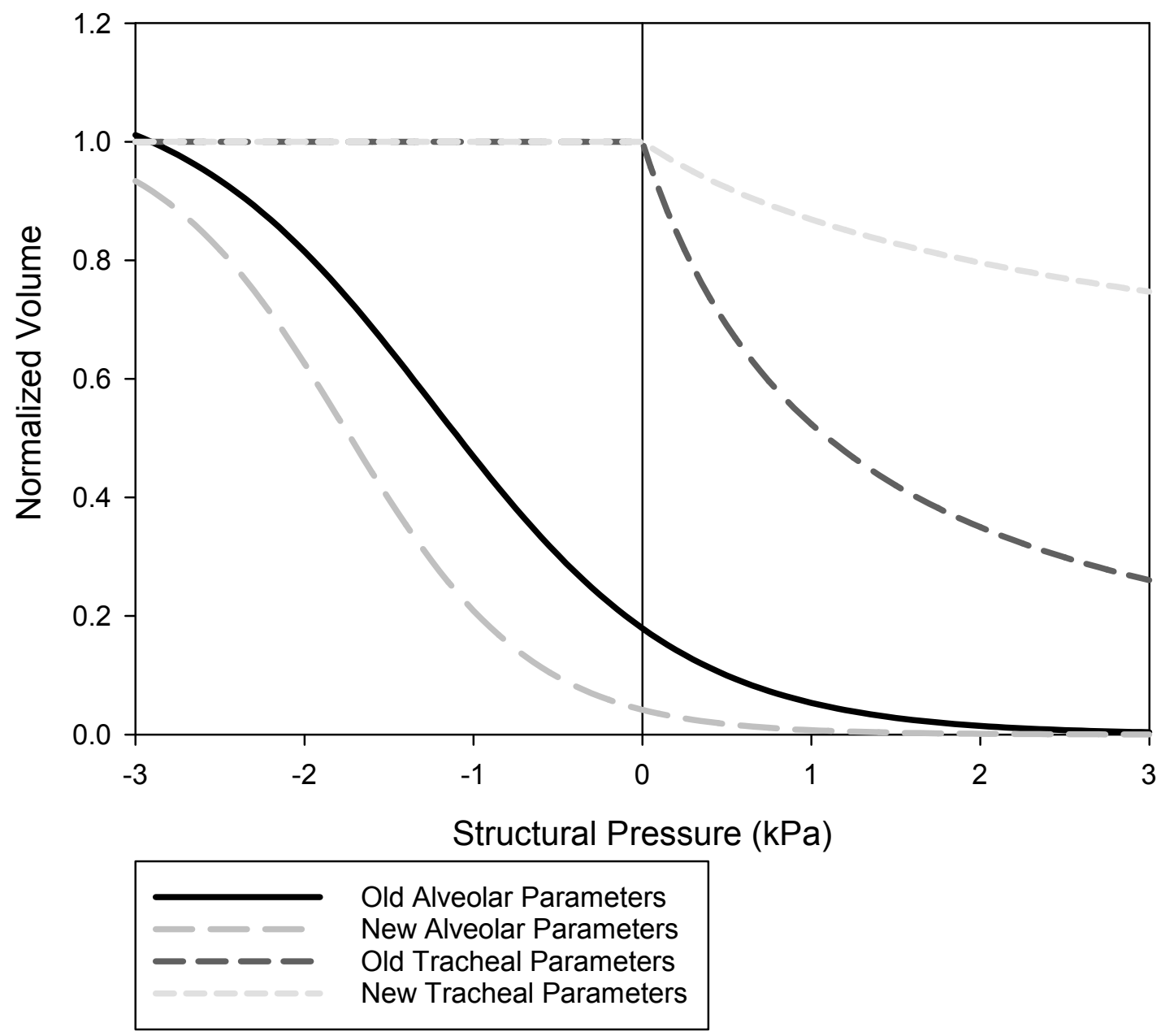




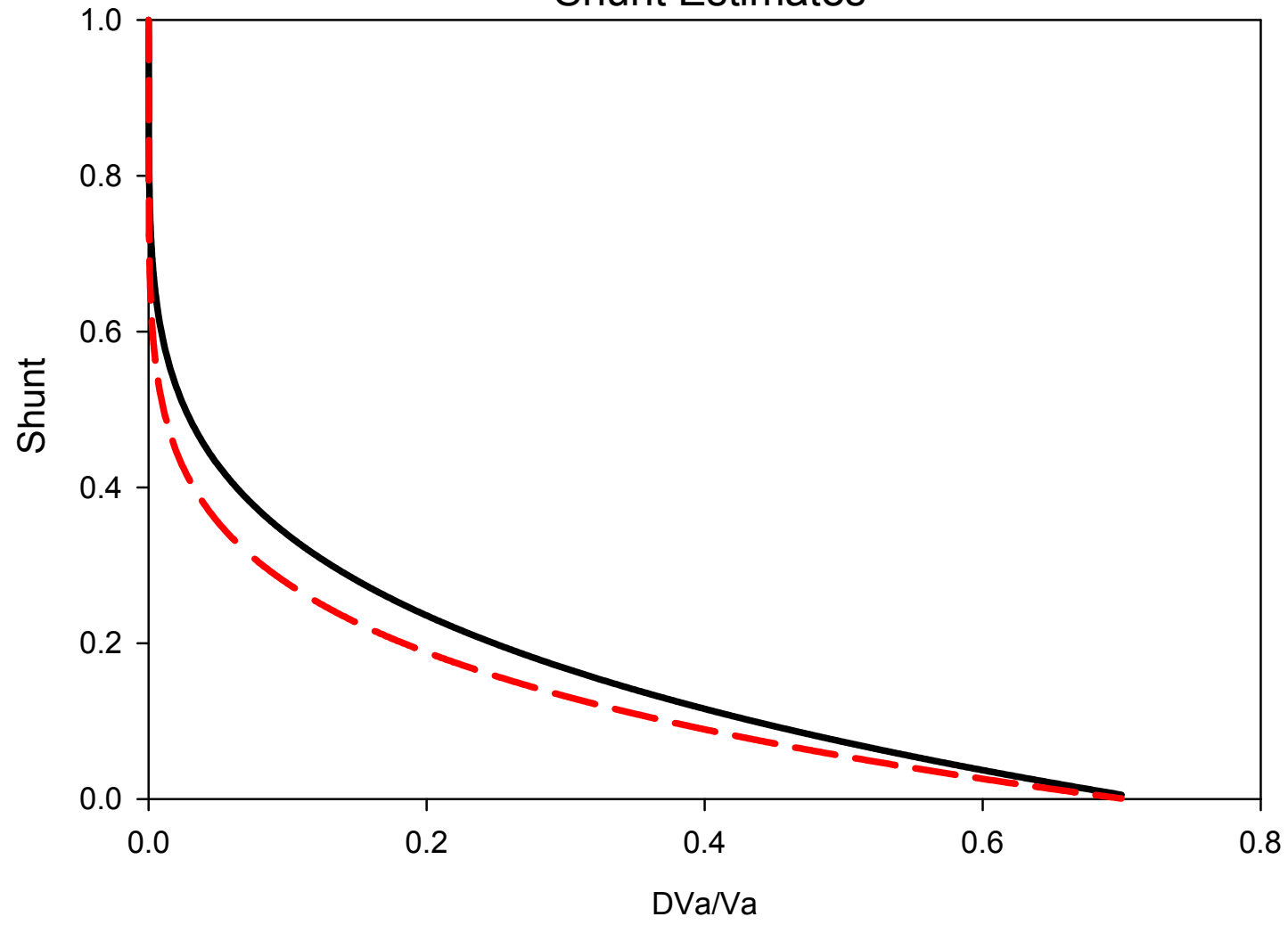

$\longrightarrow$ Old Parameters $-\quad$ New Parameters 


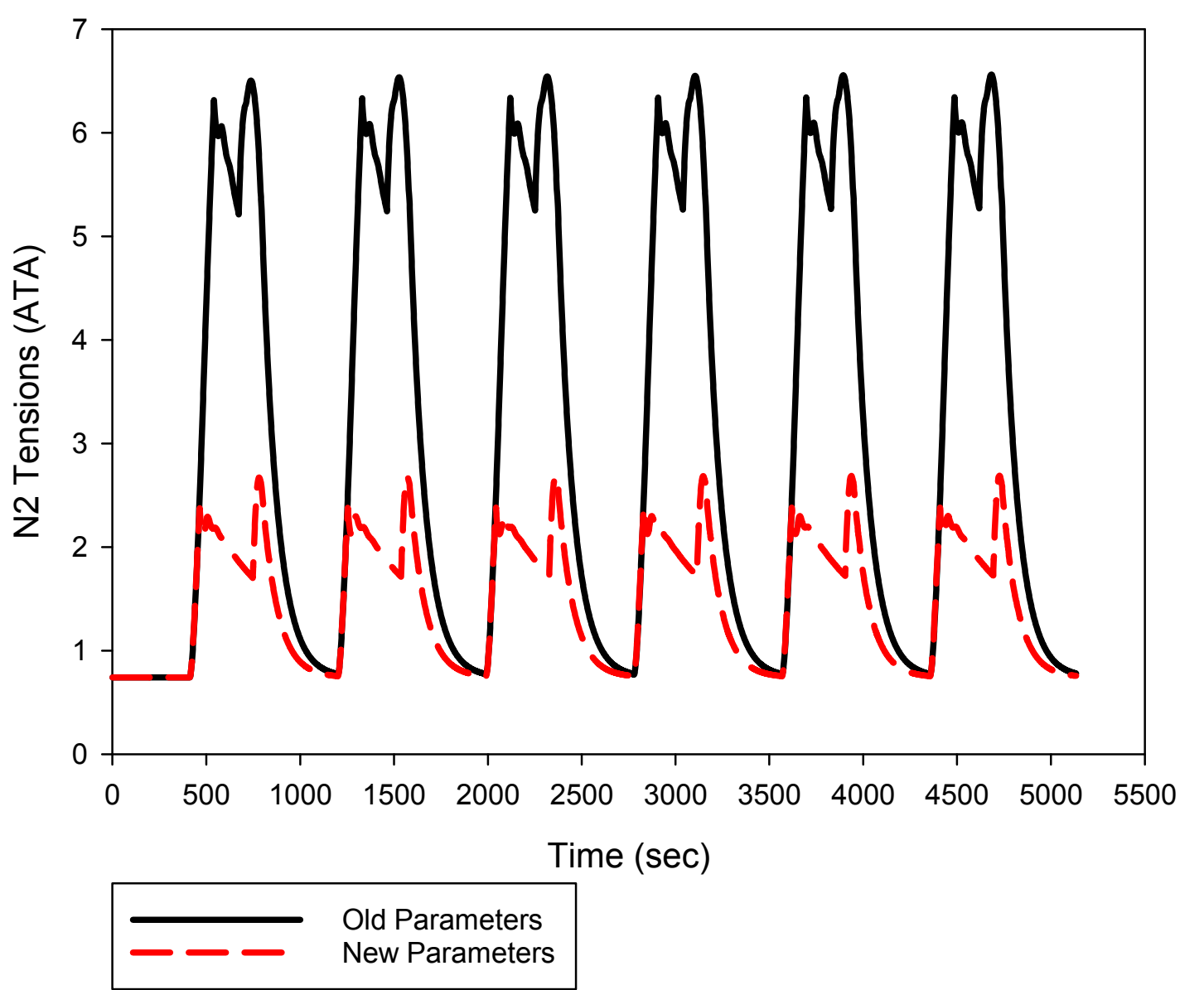


Muscle PN2
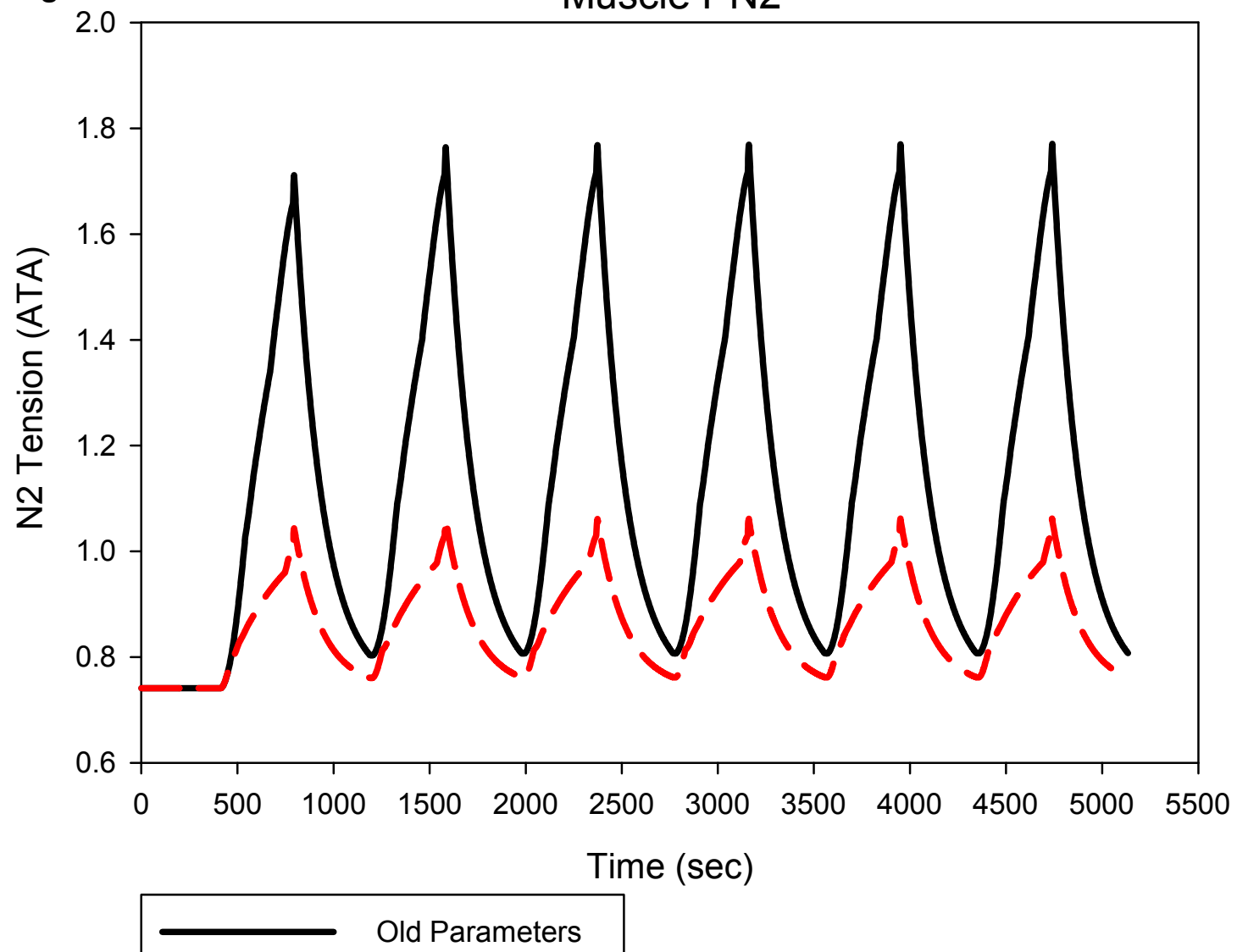

— — New Parameters 


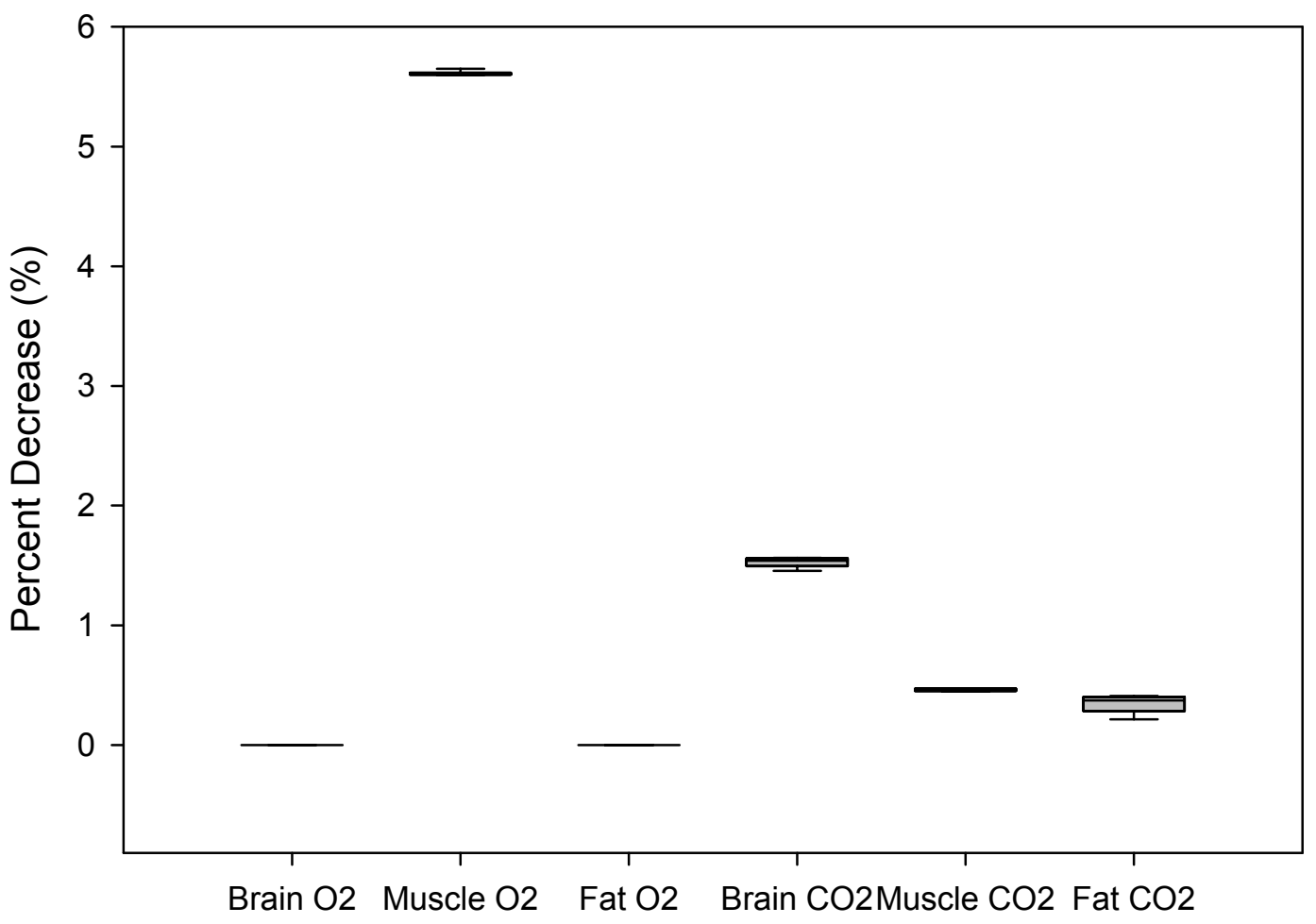

